\title{
Reconstructing Great Basin Butterfly-Pollen Interaction Networks over the Past Century
}

3

\author{
Behnaz Balmaki ${ }^{1}$, Tara Christensen ${ }^{1}$, Lee A. Dyer ${ }^{1}$ \\ (1)Department of Biology, University of Nevada, Reno, NV, 89557
}

Abstract:

Aims: Insects and the plants they interact with dominate terrestrial biomes and constitute over half of the earth's macro-organismal diversity. Their abundance in museum collections can provide a wealth of natural history data if they are collected as part of careful ecological studies or conservation programs. Here, we summarize pollen-insect quantitative networks gleaned from adult lepidopteran museum specimens to characterize these interactions and to examine how richness and frequency of butterfly-pollen associations have changed over a 100-year time series in Nevada and California. Pollen collected from well-curated butterfly specimens can provide insight into spatial and temporal variation in pollen-butterfly interactions and provide a complement to other approaches to studying pollination, such as pollinator observation networks.

Location: Great Basin and Sierra Nevada: California, Nevada

Time period: The last 100 years

Major Taxon studied: Butterflies

Methods: We estimated butterfly-pollen network parameters based on pollen collected from butterfly specimens from the Great Basin and Sierra Nevada. Additionally, we pooled interaction networks associated with specimens captured before and after 2000 to compare pollen-pollinator interaction variation under drought periods in California and Nevada in the last two decades versus previous years in the time series.

Results: Butterfly-pollen networks indicated that most pollen-butterfly species interactions are specialized and appear to be different from observational networks. Interaction networks associated with specimens captured before and after 2000 revealed that compared to previous decades, butterfly-pollen networks over the past 20 years had higher nestedness and connectance, with high pollen richness and low pollen abundance. 
31 Main conclusions: These findings represent another unique approach to understanding more

32 about pollination biology, and how butterfly-pollen interactions are impacted by climate

33 variation and ecosystem alteration.

35 Keywords: Bipartite Network, Butterflies, California, Climate Change, Museum Collections,

36 Nevada, Pollen-Pollinator Interaction, Specialization

\section{Introduction:}

39 Plant-pollinator interactions contribute substantially to biodiversity and are likely to provide

40 ecosystem stability in the face of climate change and environmental stress. Documenting

41 interactions between plants and pollinators is the first step in resolving different aspects of

42 pollinators' habitat, diet, migration, and impact on plant reproduction (Jones, 2012, 2014).

43 Pollination interaction networks are an increasingly important method for summarizing these

44 interactions, and they are frequently used to document and describe plant-visitor interactions,

45 pollen-insect interactions, and pollinator effectiveness (Ballentyne et al., 2015; Tur et al., 2016).

46 Numerous metrics at both the network and species level have been developed and can provide

47 useful quantitative summaries of pollination network properties (Gibson et al., 2011; Jauker, et

48 al., 2018). Proper interpretations of selected network parameters can help us to understand

49 pollinators' responses to habitat alteration, biodiversity change, and climate change by comparing

50 changes in interactions over time or across disturbance gradients (Proulx et al., 2005; Ballantyne

51 et al., 2015; Bohan \& Dumbrell, 2017). Analyzing network indices is also a useful tool for

52 assessing the level of generalization or specialization for species on either side of the bipartite

53 network. For example, published pollination networks have been used to estimate diet breadths

54 of pollinators that are on a continuum ranging from extreme specialists (one link between the

55 pollinator and its host plant), to extreme generalists (many links between the pollinator and its

56 host plants), but the estimates are based solely on network structure (Dormann et al., 2009;

57 Bohan \& Dumbrell, 2017; Novella-Fernandez et al., 2019). These networks are usually

58 "visitation networks," utilizing observations of insects visiting flowers, rather than analysis of

59 pollen collected from insects. 
60 Pollen analysis is commonly used in the reconstruction of past climate, vegetation history,

61 historical ecology, and biodiversity (Matthias et al., 2015; Shennan et al., 2015; Balmaki et al.,

62 2019). Palynological methods allow for comparisons of past and modern plant diversity and

63 species assemblages (Gosling et al., 2018), providing quantitative measures of landscape change

64 through time that can be linked to landscape disturbance or other perturbations to investigate

65 changes in plant communities with a focus on the impacts of climate change on natural and

66 managed ecosystems (Burjachs \& Julia, 1994; Balmaki et al., 2019; Díaz et al., 2019). Analysis

67 of pollen associated with insects is a more recently developed method that can be used for

68 addressing questions related to insect food sources and habitats (Jones, 2012; Silberbauer et al.,

69 2004), but this approach has not been utilized for examining butterfly-pollen networks. Pollen

70 persists on lepidopteran bodies through collection and curation (Courtney et al., 1982), so

71 analyzing pollen grains on butterflies can provide information on insect-pollen interactions that

72 is distinct from existing pollination network approaches. Historically, flower visitation networks

73 have served as the most common method for examining plant-pollinator interactions; for these

74 networks, visitors to flowers of a particular plant are recorded and interaction frequency is used

75 as a proxy for pollination. However, visitation does not always correspond to successful pollen

76 transfer, and this method can be an ineffective means of predicting the importance of particular

77 pollinators (King et al., 2013). Some visitors do not pick up pollen, simply remove pollen

78 without transferring it to another conspecific, or interfere with pollination by blocking the stigma

79 of the flower (Ballantyne et al., 2015). More advanced methods of studying plant-pollinator

80 interactions have emerged in recent years, and present more precise alternatives to studying

81 flower visitation (Garratt \& Potts, 2011; O'Connor et al., 2019).

82 One of the most precise methods for documenting interactions between insects and pollen (i.e.

83 not pollination per se) is to merge identification methods from palynology with samples

84 collected from insects that have been identified and curated. Museum specimens provide

85 permanent records of these interactions (Colla \& Packer., 2008; Colla et al., 2012; Bartomeus et

86 al., 2013; Scheper et al., 2014). Upon nectaring at flowers, butterflies make contact with the

87 reproductive organs of flowers and pollen is lodged onto their bodies. While butterflies are

88 foraging for nectar with their elastic proboscis, pollen grains stick to their eyes, proboscis, frons, 
90 (Willmer, 2011). Identification and quantification of the pollen grains found on the bodies of

91 butterflies or other pollinators can provide information about the plants that an individual has

92 come into contact with and can be used to create plant-pollen networks for various inferences,

93 including assumptions that these networks estimate pollination networks (Butler \& Johnson,

94 2020). Although the presence of pollen on insects is an imperfect indicator of which plants the

95 insect provides pollination services to, it suggests an interaction with the reproductive floral parts

96 of that species (Jennersten, 1984; Butler \& Johnson, 2020). This method may provide an

97 insightful alternative to the visitation networks that dominate the pollination network literature

98 (Silberbauer et al., 2004; Kleijn \& Raemakers, 2008; Jones, 2012; Scheper et al., 2014) since

99 insects in visitation networks can include parasites and incidental visitors that are not picking up

100 or transferring pollen (Ballantyne et al., 2015). Examining pollen on preserved insects is also a

101 step towards characterizing insect communities that are carrying and moving pollen at any given

102 place and time.

103 Natural history museums are an important tool for recording taxonomic diversity and can

104 provide insight into native pollinator communities across spatial and temporal gradients (Titeux

105 et al., 2017; Seltmann et al., 2017). Museums and their collections are also a key part of efforts

106 to document and predict the consequences of habitat loss, fragmentation, invasive species, and

107 climate change. The few studies that have used museum specimens to quantify insect movements

108 and temporal changes in pollinators have mostly focused on Hymenoptera (Silberbauer et al.,

109 2004; Wood et al., 2019) and have effectively documented striking spatial and temporal patterns.

110 For example, Wood et al. (2019) found that specimens from declining bumblebee species

111 exhibited a one-third decrease in pollen richness from individuals collected before and after

112 2000. Additional studies using museum specimens from different systems and with diverse

113 pollinator taxa will contribute to understanding how plant-pollen interactions and pollination

114 networks are responding to global change.

115 Overall, weather patterns in the Sierra Nevada and Great Basin are rapidly changing, and these

116 changes have been especially severe in the last two decades (McEvoy et al., 2012; Hatchett et al.,

117 2015). Substantial changes include the decreasing snowpack, decreases in annual precipitation,

118 and increased fire frequency (Belmecheri et al., 2016). Concurrently, there have been

119 considerable increases of invasions by exotic plants that are outcompeting the endemic species 
120 over the past 100 years. The proliferation of drought resistant and fire tolerant plants has

121 contributed to a decline in the density of native plants which are not adapted to these climate

122 extremes (Rondeau, 2013). These changes in plant composition necessarily result in shifting

123 pollinator communities that interact with them. One of the primary aims of this study was to

124 utilize plant-insect interaction data associated with the Lepidoptera collections at the University

125 of Nevada Museum of Natural History (UNRMNH) to examine how richness and abundance of

126 butterfly-pollen interactions have changed in the Great Basin and Eastern Sierra over the last

127 century. This time period and sampling area include multiple disturbance gradients, but the focus

128 here was on pre and post 2000 pollination networks. In order to investigate the effects of time on

129 the structure and composition of pollination networks in California and Nevada, we used

130 specimens from the invertebrate collections at the University of Nevada, Reno Museum of

131 Natural History. These specimens were all adults from the Lepidopteran superfamily,

132 Papilionoidea, commonly known as butterflies (Kawahara et al., 2019), which were collected

133 between the years of 1910 and 2020. Pollen grains were removed from these specimens and

134 identified to the species or genus level. We quantified the pollen counts and calculated

135 commonly used network parameters based on the species interaction matrix. To investigate

136 pollen-pollinator interaction variation under drought conditions in California and Nevada in the

137 last two decades, networks before and after 2000 were used to examine changes in network

138 structure over time.

\section{Methods:}

\section{Data Collection and Pollen Analysis:}

142 One hundred seventy-three Lepidopteran specimens from the most common species sampled 143 over the past century were selected from the UNR Museum of Natural History (UNRMNH) to 144 collect pollen grains from their bodies. These specimens were collected between 1910-2020 in

145 the Great Basin region of Nevada as well as the Sierra Nevada mountain range in Nevada and

146 California (Table S1). The samples represented three papilionoid (butterfly) families in

147 Lepidoptera and included 18 different species. Specimens were rinsed with 95\% ethyl alcohol

$148(\mathrm{ETOH})$ to collect all pollen grains from their external tissues, including the proboscis, legs, and

149 compound eyes (Fig.1). Entomological pins were used to remove all the pollen grains from each 
150 insect's external tissue under a binocular microscope. All recovered pollen grains were stored in

151 vials with $2000 \mathrm{cs}$ silicone oil volume and stain (Safranin-O) to highlight morphological features

152 (Jones, 2014). Representative pollen samples were mounted on glass slides by adding two drops

153 of the sample solutions to a clean glass slide, securing with a coverslip, and sealing with clear

154 nail polish. Light microscopy (LM) and a scanning electron microscope (SEM) were used for

155 pollen identification. In addition, the Great Basin pollen database at the UNRMNH was used as a

156 reference slide for pollen identification.

\section{Network and Statistical Methods:}

158 For each specimen, we quantified pollen species abundances and unique interaction frequencies

159 for each available year from 1910 to 2020 to compare patterns in diversity and abundance across

160 time. Well-established protocols were used for visualizing ecological networks and calculating

161 network parameters (e.g., Pardikes et al., 2018; Dell et al., 2019; Salcido et al., 2020), and

162 networks were analyzed using the "bipartite" package in R (Fig. 2, Appendix 1 Figure A1). The

163 nodes in the bipartite network represent the plant and pollinator (i.e. pollen-carrying) species,

164 and the edges were determined by pollen-insect associations present in museum specimens, with

165 the width of edges representing the frequency of encounter of a given interaction. We calculated

166 network indices including connectance, nestedness, network specialization (H2'), as well as

167 other commonly reported network metrics (Table S2). Connectance represents the number of

168 links between nodes over the number of species squared in a network; this parameter summarizes

169 the number of realized possible connections (Martinez, 1992). Nestedness describes the degree

170 of subsetting; compared to random networks, nested networks contain more specialized

171 interactions as distinct subsets of more generalized interactions. Different parameters have been

172 developed for nestedness, for example the NODF parameter, for which a value of 100 represents

173 a perfectly nested network, and a value of 0 represents no nestedness. Network specialization is a

174 network-level index that summarizes the degree of specialization and is useful for comparisons

175 across multiple networks. Values of network specialization range between zero and one, with

176 zero representing complete generalization and one representing complete specialization

177 (Blüthgen 2006). 
178 Based on warming events which impacted California and Nevada around 2000 (McEvoy et al.,

179 2012; Hatchett et al., 2015; Belmecheri et al., 2016), we considered two distinct pollen-pollinator

180 interaction networks; one using the data collected before 2000, and one using the data collected

181 after 2000 (Fig. 3). We calculated network parameters for these two groups to compare the level

182 of specialization for the selected butterflies over time considering the changing climate in these

183 two time periods (Table 1). Also, the richness values were included as response variables in

184 Bayesian linear models to examine changes in diversity over time for individual species (details

185 are in the supplementary materials, Appendix 2 Figure A2). Networks were not compared to null

186 networks due to the descriptive nature of the study. To improve the relevance of results to

187 pollination, plant species known to be wind-pollinated were removed from the analysis, since it

188 is likely insects picked up their pollen in the environment rather than making contact with them.

\section{Pollinator observations}

190 In order to better understand plant-pollinator interactions for some of the species examined here,

191 and to provide a brief qualitative comparison to the pollen counts found on individuals, short

192 targeted pollinator observations were conducted and combined with existing observational

193 knowledge. Two species, Lycaeides anna and L. melissa, were selected due to our familiarity

194 with the natural history of these species as well as their high abundances at the selected sites. A

195 population of L. anna was observed near Yuba Pass in eastern California, and a population of $L$.

196 melissa was observed in Verdi, Nevada on August 3, 2020 and August 11, 2020, respectively.

197 The host plant for L. anna larvae at this site is Lotus nevadensis and for L. melissa the host plant

198 is Medicago sativa. At each site, the perimeter of the sampling area was walked continuously for

199 two hours. Each time an individual was encountered, the sex of the individual was recorded, and

200 it was noted whether the individual was found on the host plant or not. In the case of L. anna, the

201 identities for all other plants visited were recorded, and all individuals found on plants were

202 observed visiting the flowers of those plants. Due to the great abundance and activity of $L$.

203 melissa at the other site, it was only possible to record whether individuals landed on their host

204 plant or were observed flying or on another plant, and individuals were found visiting flowers as

205 well as landing on stems or leaves. After the two-hour observation window, individuals were

206 collected opportunistically for pollen analysis. A total of 13 individuals from L. anna and 20 
individuals from L. melissa were captured and frozen for pollen analysis, which was completed using the same methods described for the network assessment (Appendix 3 Figure A3).

\section{Results}

\section{Pollen Analysis of Historic Lepidoptera}

212 We identified a total of 7686 individual pollen grains on the external tissues of our butterfly

213 specimens. Most of the pollen was found on the eyes, proboscis, and legs of the butterflies, and

214 we accounted for pollen from 29 different plant species. Pollen analysis from as far back as 1910

215 to the present revealed a diverse community of plant species commonly associated with

216 butterflies (Table 1). Pollen from Ambrosia dumosa (Asteraceae), Artemisia tridentate

217 (Asteraceae), Pinus sp (Pinaceae), Atriplex confertifolia (Amaranthaceae), Alnus tenuifolia

218 (Betulaceae) and Leymus cinereus (Poaceae) were found mostly on the butterflies' head and

219 wings. These species are not known to be insect pollinated, and it is likely these insects

220 inadvertently picked up their pollen from the environment; perhaps in the soil or from the wind

221 (Blauer et al., 1976). Overall, our records signified a varied range of pollen richness (range

222 between 2-11 per species) and abundance (average of 400 pollen grains per species) between

223 butterfly species as well as the date they were captured.

\section{Interaction Network and Statistical Analysis}

226 We constructed a quantitative bipartite network using 19 pollinator (butterfly) and 29 plant taxa,

227 highlighting interaction frequency, where the thickness of the bars represents pollen species

228 abundance and linkage indicates the frequency of interaction (Fig. 2). Some relevant parameters

229 examined in the bipartite interaction network include connectance, nestedness, and degree of

230 specialization (Appendix 1 Table A2). In addition, to explore how plant-pollinator interactions

231 changed over time, specimens captured before 2000 and after 2000 were analyzed separately and

232 network parameters were calculated for the respective networks (Fig. 3). Connectance values

233 increased from 0.20 to 0.23 between common species that were captured in both time intervals.

234 High H2' values for both time periods indicate substantially specialized networks (0.68). The

235 nestedness value also increased from 22.82 to 27.37 . Pollen richness over time was also

236 evaluated for the 19 butterfly species, and for most species there was in increase in the number of

237 pollen species over time. 


\section{Focused comparison of field observations to pollen analysis}

240 The composition of the types and abundances of pollen found on the two butterfly species

241 involved in the field observations differed substantially from the plants these two species were

242 observed interacting with. For Lycaeides anna, a total of 145 pollen grains representing five

243 plant taxa were found on the collected specimens. This is in contrast to the field observations

244 where individuals were found interacting with three different flower species, though two of the

245 plant taxa from the different study types overlapped, Solidago californica and Aster sp.

246 (Asteraceae). For L. melissa, a total of 119 pollen grains were counted and a total of seven plant

247 species were found on the collected specimens. Though many of the individuals were

248 encountered while flying or on other plants during the observation period for this species, they

249 were only observed interacting with the flowers of Medicago sativa.

\section{Discussion:}

252 Plant-pollinator interactions are some of the most important interactions for the maintenance of 253 terrestrial biodiversity. Constructing accurate pollination networks across variable habitats

254 provides important estimates of interactions that can help understand pollinator responses to 255 habitat reduction or fragmentation, climate change, invasions by exotic species, and changing 256 communities generally. We demonstrate that collecting pollen from museum specimens can be a 257 novel and effective means for characterizing and studying pollination interactions and niche 258 breadth in light of changing environmental pressures over time.

259 Our primary objectives were to summarize the observed pollen-butterfly interaction networks 260 and to determine changes in frequency and richness of those interactions over the last 100 years

261 in California and Nevada. We found a substantial change in pollen richness and abundance on 262 museum specimens collected in different decades. We estimated similar pollen richness over 263 time for a number of different butterfly species, including Cercyonis pegala, Nathalis iole,

264 Junonia coenia, Nymphalis antiopa, Vanessa carye, Lycaena helloides, Speyeria coronis and

265 Oeneis chryxus from 1910 to present, which suggested that niche breadth and pollen interactions 266 for these species have changed very little in these species over the last 100 years. However, a 
267 large increase in pollen richness was observed for several species, including Hesperia

268 juba, Speyeria egleis and Cercyonis sthenele, indicating some pollinator species may be

269 expanding their niche breadth in response to, or rather in spite of, environmental change (Table

270 S2). Alternatively, plant communities have shifted such that available pollen richness has

271 increased and is reflected on the specimens gleaned from butterflies.

272 Although our results indicate some mild increases in network specialization over time, most

273 butterflies including specialized species may utilize novel plants when focal resources are scarce,

274 and such switching may help stabilize ecosystem processes (Dunne et al., 2002; Tylianakis et al.,

275 2010). The networks observed in our study had connectance values around 0.20, which is higher

276 than what is commonly reported in the literature for visitation networks (Dunne et al., 2002).

277 This may indicate that pollen-butterfly interactions are comprised of a higher degree of

278 interaction complexity that what is estimated from visitation networks. We also found that the

279 networks analyzed had a high level of nestedness, which is linked to high levels functional

280 redundancy, which is also a stabilizing factor for biotic communities.

281 Another objective of this study was to investigate how climate change has impacted pollen-

282 butterfly interactions over time. In 2015, the snowpack in the Sierra Nevada mountains was only

283 five percent of its historical average, a clear indication of long-term drought in the region

284 (Belmecheri et al., 2016). This is part of an overall trend of increasing drought in the Sierra

285 Nevada and Great Basin regions. Droughts are known to negatively affect pollinators by

286 decreasing the quantity and quality of floral rewards (Phillips et al., 2018). Our study

287 documented clear shifts in pollen-butterfly interactions before and after the onset of drought,

288 based on the more common specimens of Lepidoptera at the UNRMNH (Fig.3). We found that

289 the interaction network after 2000 is characterized by decreased pollen loads compared to before

290 2000, except in a few butterfly species. We even observed some specimens that were captured

291 after 2000 with no pollen on their body. Pollen-butterfly interaction links decreased in Polygonia

292 satyrus, Phyciodes mylitta, Nymphalis antiopa, and Cercyonis sthenele. For two species,

293 Hesperia juba and Speyeria egleis, pollen richness and abundance increased.

294 Our networks indicated that species that were captured after 2000 are more specialized, which

295 could be a consequence of lower resource availability. The long-term increase in pollen richness

296 with low abundance is correlated with increased drought in California and Nevada in the last two

297 decades. These areas are facing drought that has resulted in increasing and more intense 
wildfires, and warming temperatures that cause precipitation to fall as rain rather than snow.

299 These changing climate factors are strongly impacting plant communities with which pollinators

300 interact, often priming them for invasion by exotic species and a decrease in abundance of native

301 plants. While butterflies may be confronting a narrower nectar and pollen niche breadth, some

302 may form novel interactions with new plant resources, increasing numbers of interactions over

303 time; such increases in interactions are often associated with increasing stability. Network

304 connectance, which depends on potential interactions in the network, also increased after 2000,

305 and was partly driven by increased niche breadths of a few species, like S. egleis, H. juba and N.

306 antiopa in the last decades. Related to these patterns, the most common pollen species

307 represented in our networks, E. nauseosa (Rubber rabbitbrush) and Monardella sp sharply

308 declined in abundance in the last two decades compared to the years before 2000; this may be

309 linked to habitat loss and ecosystem alteration in the last two decades.

310 Finally, the focused observations of two butterfly species, L. Melissa and L. anna, along with

311 decades of natural history observations, provided a snapshot of the differences between

312 interactions observed in the field (which were designed to mirror widely used visitation network

313 methods) and interactions inferred from pollen found on the specimens' bodies. Though there

314 was overlap between the observations and the pollen composition found on L. anna, there was no

315 pollen from the larval hostplant (Medicago sativa) found on the bodies of L. Melissa collected in

316 the field in spite of frequent observed interactions between adult moths and flowers for these

317 species. This result highlights potential shortcomings of visitation networks as well as the

318 method used in this paper; the visitation networks clearly underestimate diversity of pollen

319 picked up by butterflies, and in the case of our method, we did not see pollen abundances

320 associated with frequent visitation of a focal flower. These observations were very limited in

321 temporal and spatial extent, but they underscore the importance of combining multiple methods

322 for estimating true networks.

\section{Conclusion}

325 In a time of growing concern about insect declines, we present a case for the use of museum

326 specimens in describing changes in interaction networks over time. Much media coverage has

327 been directed at the declines in pollinators in recent decades (Biesmeijer et al., 2006; Colla \& 
328 Packer., 2008; Wood et al., 2019), and long-term data sets have been used to validate these

329 trends (Cola et al., 2012; Bartomeus et al., 2013; Wood et al., 2019). An advantage of using

330 museum specimens is that the collection events may span decades or even more than a century,

331 allowing for reconstruction of past interaction networks. The use of museum specimens also

332 comes with its disadvantages; pollen may fall off or be removed from specimens, there is a lack

333 of standardization in the collection methods, and a host of other factors that can vary across taxa

334 and collections. Also, there will likely be uneven sampling over the years that could generate

335 data that is highly variable over time. However, every approach to describing and quantifying

336 mutualistic networks has disadvantages, and perfect characterizations of species interaction

337 networks are impossible at broad spatial and temporal scales. This approach combined with the

338 more popular visitation networks, and studies of pollinator effectiveness (Ballantyne et al.,

339 2015), could lead to a thorough understanding of pollination interaction networks and how they

340 change across disturbance gradients.

\section{Acknowledgments}

343 We are grateful to those who captured and collected butterflies for the museum and to M. Forister

344 for helpful comments on this manuscript. Also, we would like to say thank you to the University

345 of Nevada Reno Museum of Natural History (UNRMNH) for funding this research and giving us

346 this opportunity to work on these valuable collections.

\section{References}

348 Ballantyne, G., Baldock, K.C.R., \& Willmer, P.G. (2015). Constructing more informative plant349 pollinator networks: visitation and pollen deposition networks in a heathland plant community.

350 Proc. R. Soc, B 282, 20151130.

351 Balmaki, B., Wigand, P., Frontalini, F., Shaw, A. T., Avnaim-Katav, S., \& Asgharian Rostami, 352 M. (2019). Late Holocene Paleoenvironmental Changes in the Seal Beach Wetland (California, 353 USA): A Micropaleontological Perspective. Quaternary International, 530-531, 14-24. 
354 Banza, P., Macgregor, C.J., Belo, A.D.F., Fox, R., Pocock, M.J.O., \& Evans, D. 2019. Wildfire

355 alters the structure and seasonal dynamics of nocturnal pollen-transport networks. Functional

356 Ecology, 33, 1882-1892.

357 Bartomeus, I., J. S. Ascher, J. Gibbs, B. N. Danforth, D. L. Wagner, S. M. Hedtke., \& Winfree.

358 R. (2013). Historical changes in northeastern US bee pollinators related to shared ecological

359 traits. Proceedings of the National Academy of Sciences, 110, 4656-4660.

361 Bascompte, J., Jordano, P., \& Melián, C. J. (2003). The nested assembly of plant-animal

362 mutualistic networks. Proceedings of the National Academy of Sciences, 100 (16), 9383-9387.

364 Belmecheri, S., Babst, F., Wahl, E. R., Stahle, D.W., \& Trouet, V. (2016). Multi-century

365 evaluation of Sierra Nevada snowpack. Nature Climate Change, 6, 2-3.

367 Biesmeijer, J.C., Roberts, S.P.M., Reemer, M., Ohlemu“ller, R., Edwards, M., Peeters, T.,

368 Schaffers, A.P., Potts, S.G., Kleukers, R., Thomas, C.D., Settele, J., \& Kunin, W.E. (2006).

369 Parallel declines in pollinators and insect pollinated plants in Britain and the Netherlands.

370 Science, $313,351-354$.

372 Blauer, A. Clyde; Plummer, A. Perry; McArthur, E. Durant \& et al. (1976). Characteristics and 373 hybridization of important Intermountain shrubs. II. Chenopod family. Res. Pap, INT-177.

375 Ogden, U.T: U.S. Department of Agriculture, Forest Service, Intermountain Forest and Range 376 Experiment Station. 49 p. 473.

378 Blüthgen, N., Menzel, F. \& Blüthgen, N. (2006). Measuring specialization in species interaction 379 networks. BMC Ecology, 6, 9.

381 Bohan, D.A. \& Dumbrell, A.J. (2017). Advances Ecological Research. Elsevier, 57, 303. 
383 Burjachs, F. \& Julia, R. (1994). Abrupt Climatic Changes during the Last Glaciation Based on

384 Pollen Analysis of the Abric Romani, Catalonia, Spain. Quaternary Research, 42(3), 308-315.

386 Butler, H. \& Johnson, S. (2020). Butterfly-wing pollination in Scadoxus and other South African

387 Amaryllidaceous. Botanical Journal of the Linnean Society, 193, 363-374.

Colla, S.R., Gadallah, F., Richardson, L., Wagner, D., \& Gall, L. (2012). Assessing declines of

390 North American bumble bees (Bombus spp.) using museum specimens. Biodiversity

391 Conservation, 21, 3585-3595.

392 Colla. R.S., \& Packer, L. (2008). Evidence for decline in eastern North American bumblebees

393 (Hymenoptera: Apidae), with special focus on Bombus affinis Cresson. Biodiversity

394 Conservation, 17,1379-1391.

395 Courtney, S. P., C. J. Hill., \& Westerman, A. (1982). Pollen Carried for Long Periods by

396 Butterflies. Oikos, 38, 260-263.

398 Dell, J.E., Salcido, D.M., Lumpkin, W., Richards, L.A., Pokswinski, S.M., Loudermilk, E.L., 399 O’Brien, J.J., \& Dyer, L.A. (2019). Interaction Diversity Maintains Resiliency in a Frequently 400 Disturbed Ecosystem. Frontiers in Ecology and Evolution, 145(7), 1-9.

402 Díaz, F.P., Latorre, C., Carrasco-Puga, G., Wood, J.R., Wilmshurst, J.M., Soto, D.C., Cole, T.L., 403 Gutiérrez, R.A. (2019). Multiscale climate change impacts on plant diversity in the Atacama 404 Desert. Global Change Biology, 25,1733-1745.

406 Dormann, C.F., Frund, J., Bluthgen, N., \& Gruber B. (2009). Analyzing Bipartite Ecological 407 Networks. Open Ecology Journal, 2, 7-24.

410 Dunne J. A., Williams R. J., \& Martinez N.D. (2002). Food-web structure and network theory:

411 The role of connectance and size. Proceedings of the National Academy of Sciences of the 412 United States of America,99(20),12917-12922. 
414 Garratt, M. P. D. \& Potts, S. G. (2011). Data from: Monitoring insect pollinators and flower

415 visitation: The effectiveness and feasibility of different survey methods. Dryad Digital

416 Repository.

417 Gibson, R. H., B. Knott, T. Eberlein, \& J. Memmott. (2011). Sampling method influences the 418 structure of plant-pollinator networks. Oikos, 120,822-831.

419 Giesecke, T., Wolters, S., Jahns, S., \& Brande, A. (2012). Exploring Holocene changes in 420 palynological richness in northern Europe did postglacial immigration matters. PLoS ONE, 7, 142112.

422 Gosling, W.D., Julier, A.C.M., Adu-Bredu, S., Djagbletey, G.D., Fraser, W.T., Jardine, P.E.,

423 Lomax, B.H., Malhi, Y., Manu, E.A., Mayle, F.E., \& Moore, S. (2018). Pollen-vegetation

424 richness and diversity relationships in the tropics. Vegetation History and Archaeobotany, 27, $425 \quad 411-418$.

426 Hatchett, B. J., Boyle, D. P., Putnam, A. E., \&Bassett, S. D. (2015). Placing the 2012-2015

427 California-Nevada drought into a paleoclimatic context: Insights from Walker Lake, California428 Nevada, USA. Geophysics Research Letter, 42, 8632-8640.

429 Jauker, F., Jauker, B., Grass, I., Steffan_Dewenter, I., \&Wolters, V. (2018). Partitioning wild 430 bee and hoverfly contributions to plant-pollinator network structure in fragmented habitats. 431 Ecology. 100(2), e02569.

432 Jennersten, O. (1984). Flower visitation and pollination efficiency of some North European 433 butterflies. Oecologia, 63, 80-89.

434 Jones, G.D. (2014). Pollen analyses for pollination research, acetolysis. Journal of Pollination 435 Ecology. 13(21), 203-217.

437 Jones, G.D. (2012). Pollen extraction from insects. Palynology, 36(1), 86-109. 
439 Kawahara, A. Y., Plotkin, D., Espeland, M., Meusemann, K., Toussaint, E. F. A., Donath, A., ...

440 Breinholt, J.W. (2019). Phylogenomics reveals the evolutionary timing and pattern of butterflies

441 and moths. Proceedings of the National Academy of sciences of the United States of America,

$442116,22657-22663$.

443 King, C., Ballantyne, G., \& Willmer, P.G. (2013). Why flower visitation is a poor proxy for

444 pollination: measuring single-visit pollen deposition, with implications for pollination networks

445 and conservation. Methods in Ecology and Evolution, 4(9), 811-818.

446 Kleijn, D., \& Raemaker, I. (2008). Retrospective analysis of pollen host plant use by stable and

447 declining bumble bee species. Ecology, 89(7),1811-1823.

448 Martinez, N. (1992). Constant Connectance in Community Food Webs. The American

449 Naturalist, 139(6), 1208-1218.

450 Matthias, I., Semmler, M.S.S., \& Giesecke, T. (2015). Pollen diversity captures landscape

451 structure and diversity. Journal of Ecology, 103, 880-890.

452 McEvoy, D.J., Huntington, J.L., Abatzoglou, J.T., \& Edwards, L.M. (2012). An Evaluation of

453 Multiscalar Drought Indices in Nevada and Eastern California. Earth Interactions, 16(18), 1-18.

454 Novella-Fernandez, R., Rodrigo, A., Arnan, X., \& Bosch, J. (2019). Interaction strength in 455 plant- pollinator networks: Are we using the right measure?. PLoS ONE, 14(12), e0225930.

456 O'Connor, R.S., Kunin, W.E., Garratt, M.P.D., Potts, D.G., Roy, H.E., Andrews, C., ... Carvell, 457 C. (2019). Monitoring insect pollinators and flower visitation: The effectiveness and feasibility 458 of different survey methods. Methods Ecology Evolution, 10, 2129-2140.

459 Pardikes, N.A., Lumpkin, W., Hurtado, P.J., \& Dyer, L.D. (2018). Simulated tri-trophic 460 networks reveal complex relationships between species diversity and interaction diversity. PLOS 461 ONE, 13, 1-20. 
463 Phillips, B.B., Shaw, R.F, Holland, M.J, Fry, E.L., Bardgett, R.D., Bullock, J.M., \& Osborne, 464 J.L. (2018). Drought reduces floral resources for pollinators. Global Change Biology, 24, 32264653235.

467 Proulx, S.R., Promislow, D.E.L., \& Phillips, P.C. (2005). Network thinking in ecology and 468 evolution. Trends Ecology Evolution, 20, 345-353.

469 Rondeau, R.J. (2013). Vegetation Response in a Colorado Grassland-shrub Community to 470 Extreme Drought: 1999-2010. The American Midland Naturalist, 170,14-25.

472 Salcido, D.M., Forister, M., Lopez, H.G., \& Dyer, L.A. (2020). Loss of dominant caterpillar 473 genera in a protected tropical forest. Scientific Report, 10, 422.

474 Scheper, J., Reemer., M., Kats, R.V., Ozinga, W.A., Linden, G.T.J.V.D, Schaminee, J.H., Siepel, 475 H., \& Kleijn, D. (2014). Museum specimens reveal loss of pollen host plants as key factor 476 driving wild bee decline in The Netherlands. PNAS, 111(49), 17552-17557.

481 Shennan, L., Long, J.A., \& Horton, P.B. (2015). Handbook of Sea-Level Research. Wiley.

482 Silberbauer, L., Yee, M., Socorro, A.D., Weatten, S., Gregg, P., \& Bowie, M. (2004). Pollen

483 grains as markers to track the movements of generalist predatory insects in agroecosystems.

484 International Journal of Pest management, 50(3), 165-171.

486 Titeux, N., Henle, K., Mihoub, J.B., Regos, A., Geijzendorffer, I.R., Cramer, W., Verburg, P.H., 487 \& Brotons, L. (2017). Global scenarios for biodiversity need to better integrate climate and land 488 use change. Diversity and Distributions, 23, 1231-1234. 
490 Tur. C., Sáez, A., Traveset. A., \& Aizen, M.A. (2016). Evaluating the effects of pollinator-

491 mediated interactions using pollen transfer networks: evidence of widespread facilitation in south

492 Andean plant communities. Ecology Letters, 19,576-586.

493

494 Tylianakis, J.M., Laliberte, E., Nielsen, a., \& Bascompte, J. (2010). Conservation of species

495 interaction networks. Biological Conservation, 143(10), 2270-2279.

496 Willmer, P. (2011). Pollination and Floral Ecology. Princeton University Press.

497 Wood, T.J., Gibbs, J., Graham, K.K., \& Isaacs, R. (2019). Narrow pollen diets are associated

498 with declining Midwestern bumble bee species. Ecology 100(6), e0193822. 1-20. e02697.

500 Data Availability Statement:

501 The data that support the findings of this study are openly available at

502 http://dx.doi.org/10.6084/m9.figshare.13236989 and in the supplementary material of this article.

504 Biosketch:

505 Behnaz Balmaki is a post-doctoral researcher interested in environmental data analyst with 506 interests in research questions relating to palynology, paleoecology, and paleoclimatology. Her 507 current research is largely focused on pollen-pollinator interaction and pollinator responses to 508 the past and future climate change.

509 Lee A. Dyer uses observational, experimental, and quantitative approaches to study chemically 510 mediated plant-insect interactions in temperate and tropical ecosystems. He enjoys poetry, rock 511 climbing, natural history, and applied statistics.

512 Tara Christensen is a $\mathrm{PhD}$ student interested in plant-insect interactions and insect disease 513 dynamics. She is interested in direct and indirect interactions between insect functional guilds 514 and the plants that mediate those interactions. 
bioRxiv preprint doi: https://doi org/10.1101/2020.12 25.424352; this version posted December 27, 2020. The copyright holder for this preprint (which was not certified by peer review) is the author/funder, who has granted bioRxiv a license to display the preprint in perpetuity. It is made available under aCC-BY-NC-ND 4.0 International license.

516

517 Table 1. list of the butterflies species, number of pollen loads and number of plant species richness on each buttefly

518 species.

\begin{tabular}{|c|c|c|c|c|}
\hline Species & Family & $\begin{array}{l}\text { Number of pollen loads } \\
\text { (Insect- pollinated } \\
\text { plants) }\end{array}$ & $\begin{array}{l}\text { Number of pollen loads } \\
\text { (wind- pollinated plants) }\end{array}$ & $\begin{array}{l}\text { Number of the plant } \\
\text { species richness } \\
\text { (Insect- pollinated plants) }\end{array}$ \\
\hline Speyeria egleis & Nymphalidae & 53 & 71 & 3 \\
\hline Nathalis iole & Pieridae & 39 & 9 & 2 \\
\hline Hesperia juba & Hesperiidae & 129 & 39 & 9 \\
\hline Cercyonis sthenele & Nymphalidae & 89 & 21 & 1 \\
\hline Junonia coenia & Nymphalidae & 1193 & 90 & 8 \\
\hline Colias eurytheme & Pieridae & 51 & 6 & 3 \\
\hline Phyciodes mylitta & Nymphalidae & 220 & 55 & 4 \\
\hline Polygonia satyrus & Nymphalidae & 190 & 159 & 4 \\
\hline Nymphalis antiopa & Nymphalidae & 54 & 43 & 2 \\
\hline Vanessa carye & Nymphalidae & 309 & 11 & 5 \\
\hline Euphydryas chalcedona & Nymphalidae & 1349 & 14 & 7 \\
\hline Anthocharis sara & Pieridae & 18 & 78 & 1 \\
\hline Lycaena helloides & Lycaenidae & 212 & 171 & 4 \\
\hline Speyeria coronis & Nymphalidae & 726 & 21 & 5 \\
\hline Lycaeides melissa & Lycaenidae & 85 & 34 & 4 \\
\hline Cercyonis pegala & Nymphalidae & 1393 & 138 & 5 \\
\hline Oeneis chryxus & Nymphalidae & 220 & 66 & 6 \\
\hline Plebejus icarioides & Lycaenidae & 116 & 54 & 5 \\
\hline Lycaeides anna & Lycaenidae & 138 & 7 & 4 \\
\hline Lycaeides anna & Lycaenidae & 138 & 7 & 4 \\
\hline
\end{tabular}

519 


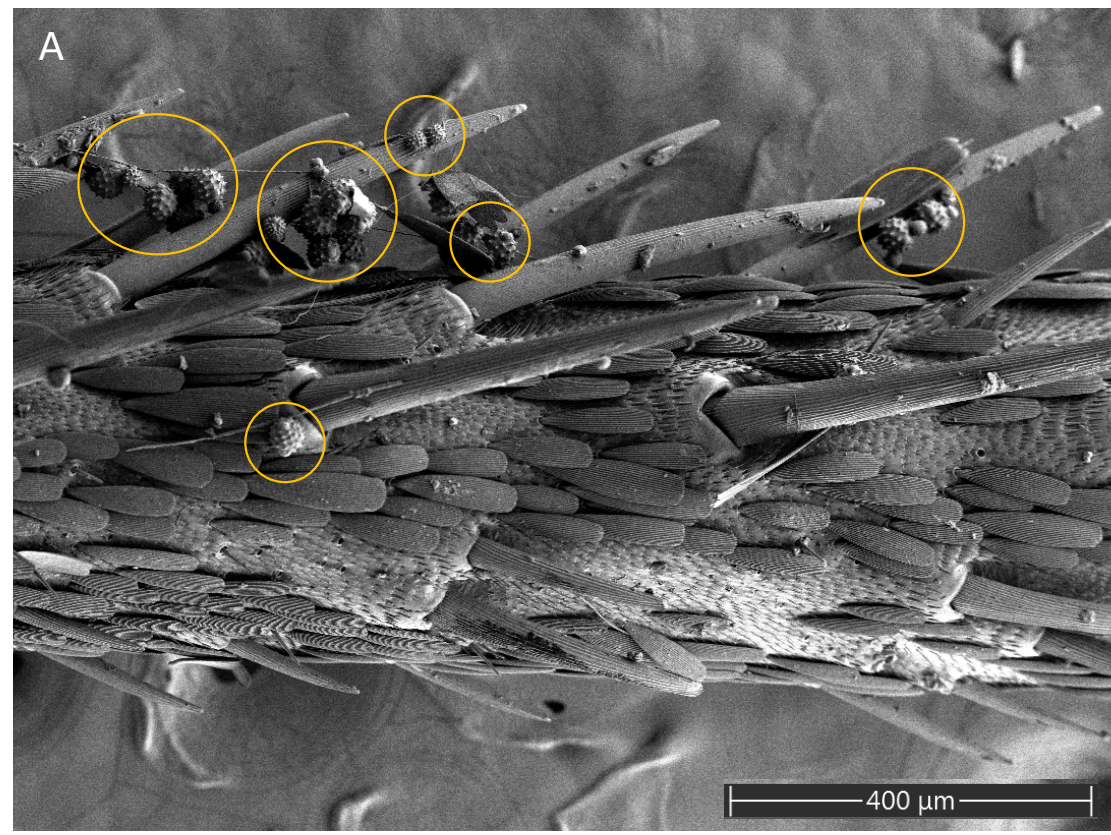

B

522 Figure 1. A-C: Scanning electron micrograph of pollen grains on butterfly legs and eyes from the collection at the

523 UNRNHM. A-B: Asteraceae pollen covering the leg of a nymphalid butterfly. C: Pine pollen on a butterfly eye. 
bioRxiv preprint doi: https://doi.org/10.1101/2020.12.25.424352; this version posted December 27, 2020. The copyright holder for this preprint (which was not certified by peer review) is the author/funder, who has granted bioRxiv a license to display the preprint in perpetuity. It is made available under aCC-BY-NC-ND 4.0 International license.

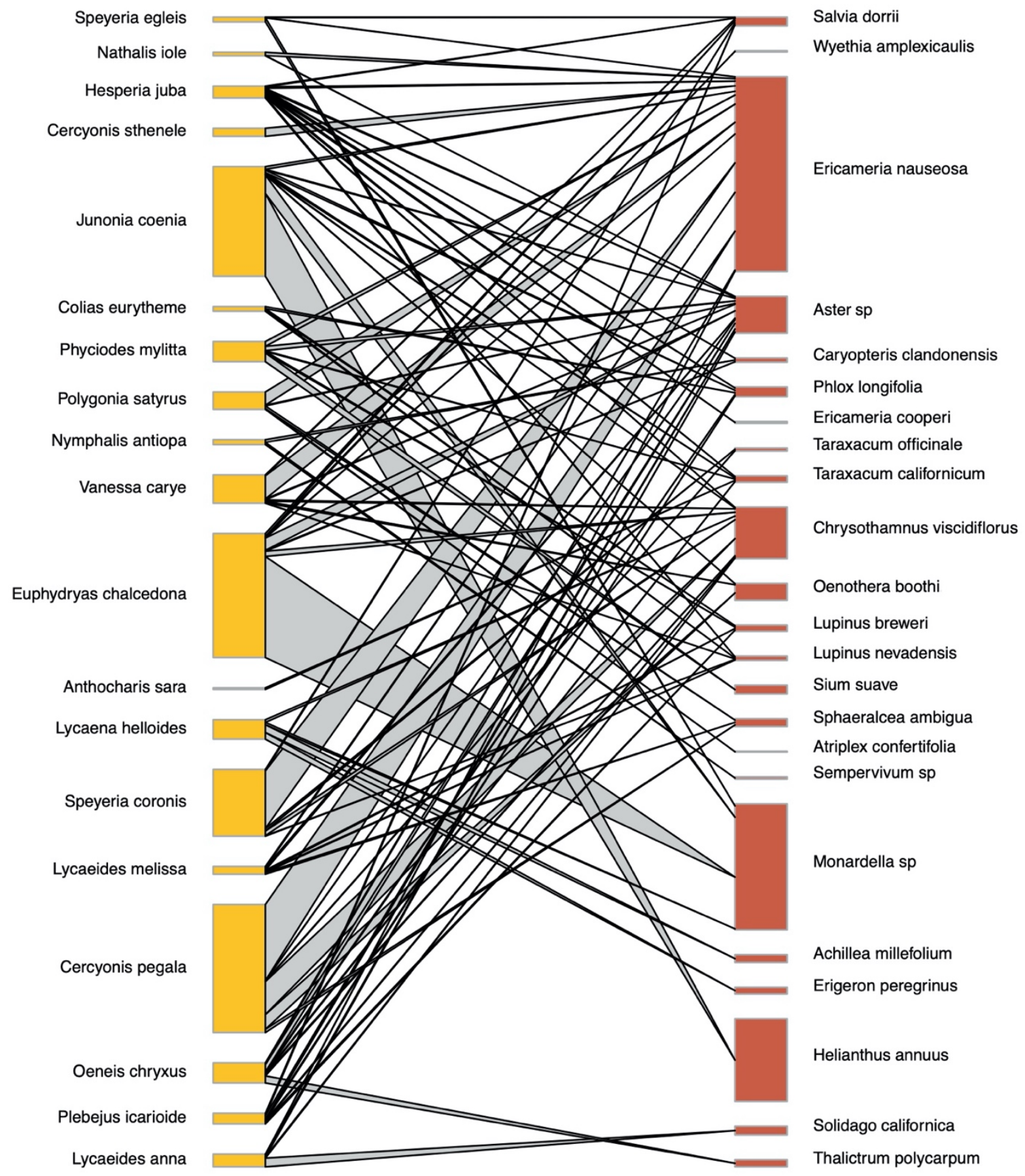

525 Figure 2. Bipartite pollination network of 19 pollinators and pollen from 29 plant species. Links between plants and 526 pollinators are represented with lines whose width is proportional to the number of interactions while the width of 527 the nodes represents total abundance of that taxon across all of its interactions. 
bioRxiv preprint doi: https://doi.org/10.1101/2020.12 25.424352; this version posted December 27 2020. The copyright holder for this preprint (which was not certified by peer review) is the author/funder, who has granted bioRxiv a license to display the preprint in perpetuity. It is made available under aCC-BY-NC-ND 4.0 International license.

A

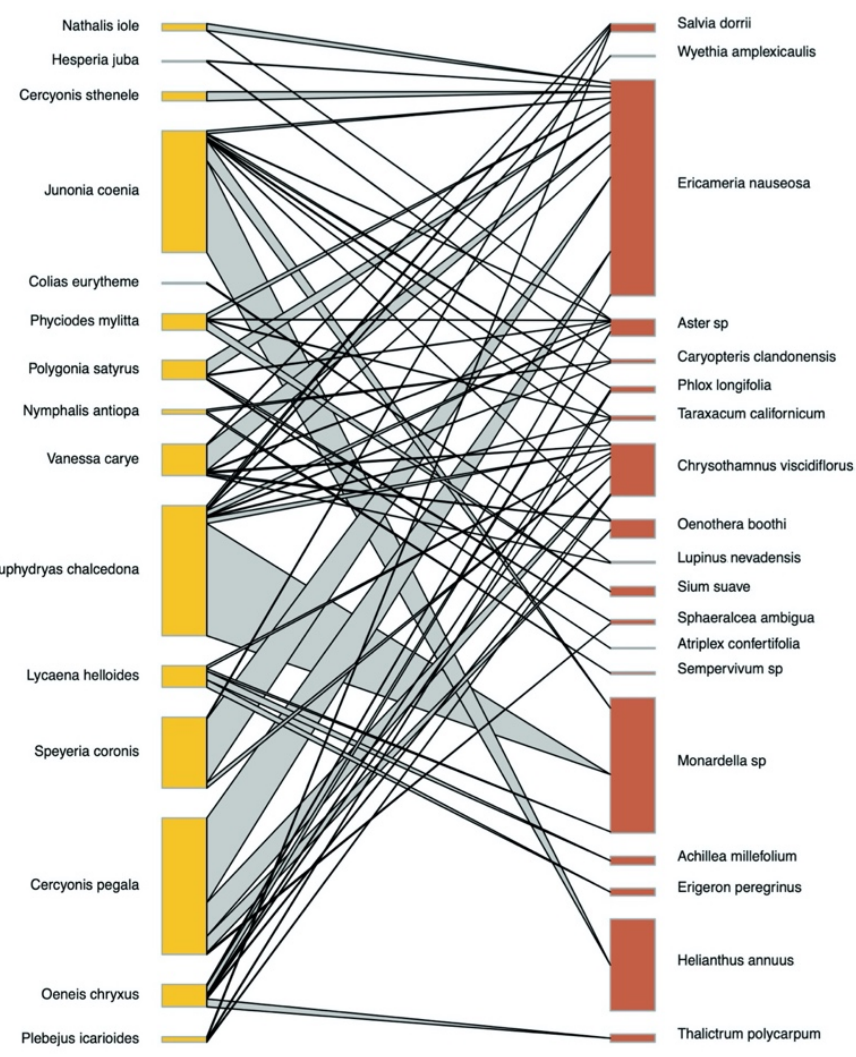

B

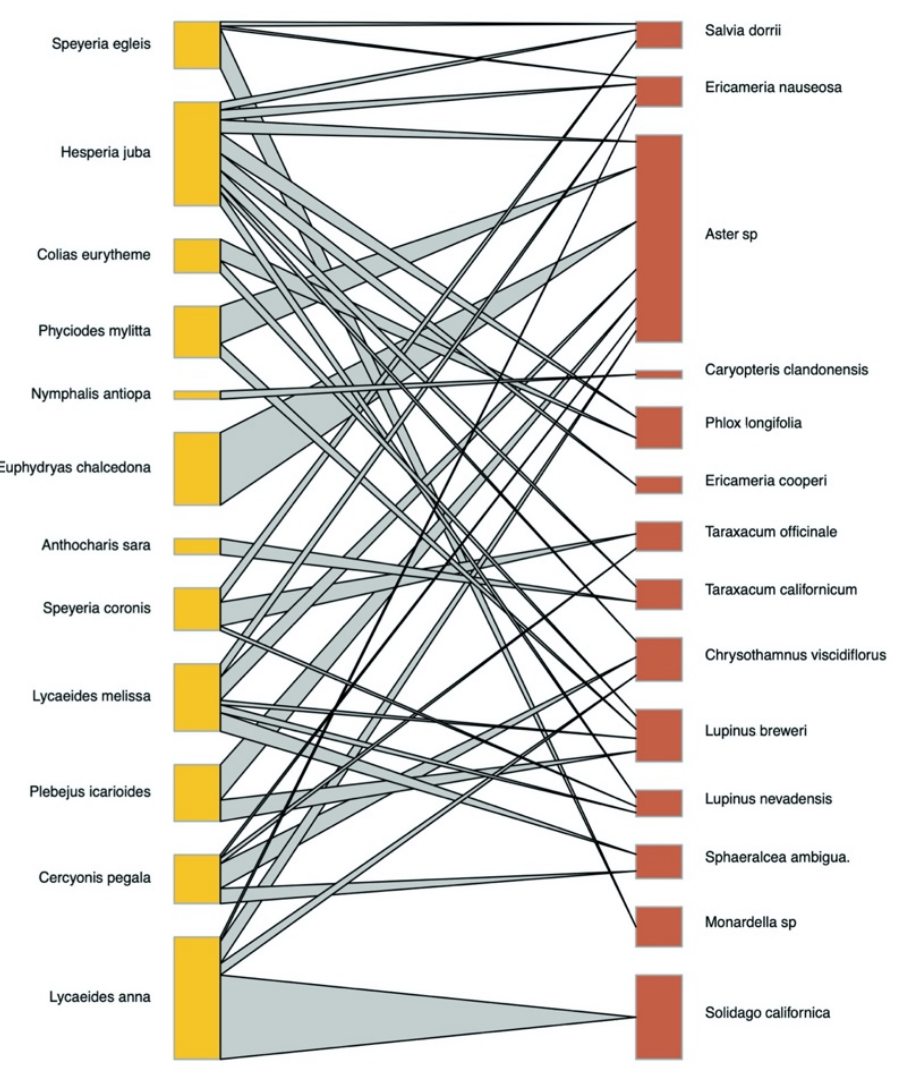

529 Figure 3. Bipartite pollination networks A: Before 2000, B: After 2000. 